\title{
The role of transobturaor vaginal tape (TOT) in the management of female stress urinary incontinence - 2 year follow up, Minia University experience Ahmed M. Abdelghany \\ Department of Obstetric and Gynecology, Faculty of Medicine, Minia University, Minia, Egypt Corresponding author: Ahmad M. Abdel ghany, Email: ahmedabdelghany28@yahoo.com
}

\begin{abstract}
Objective: The aim of this study was to evaluate the effectiveness and safety of minimally invasive surgical procedure trans-obturator vaginal tape (TOT) in the treatment of female stress urinary incontinence and follow up these cases for 24 months regarding effectiveness, safety and possibility of complications.

PATIENTS: 30 women with genuine stress urinary incontinence (SUI) demonstrated by history, clinical examination and urodynamic study.

METHODS: 30 patients diagnosed with SUI underwent transobturator sling (inside-out technique) (TVT-O Gynecare ${ }^{\circledR}$, Johnson\& Johnson, USA.) The patients were followed up for 24 - months regarding subjective and objective cure rates.
\end{abstract}

RESULTS: The mean operative time (min.) was $19.67( \pm 8.06)$. The mean intraoperative blood loss (ml) was $80 \pm 30.52$. There was no case complicated by intraoperative bleeding (mild or severe), bladder, urethral, vascular injuries and anesthetic complications. Subjective and objective cure rates of these patients were (95\%) both.

Conclusion: The results of this study concluded that management of genuine stress urinary incontinence by transobturator vaginal tape (TVT-O) is an easy and safe method with low complications and high success rate.

Keywords: Stress urinary incontinence - Transobturator vaginal tape.

\section{INTRODUCTION}

Urinary incontinence is a significant health problem in the developed and the developing countries. Population studies have shown that about $10-35 \%$ of all women have urinary incontinence ${ }^{(1)}$. Stress urinary incontinence (SUI) is the most common type of incontinence. A lot of different techniques are used for the treatment of SUI; slings are the most effective and durable form of treatment (2). Various tissues and synthetic materials are used for that purpose. The new synthetic materials, replacing the torn fascia, are the basis of the recent development of a multitude of surgical techniques of SUI and other pelvic floor lesions. The tension-free vaginal tape (TVT) procedure has revolutionized the surgery of female SUI, and it is now considered by many surgeons to be the gold-standard surgery for female SUI with excellent long-term efficacy ${ }^{(3)}$. The TVT procedure, which uses a retropubic route, has been associated with a number of complications resulting from penetrations of the surgical device into pelvic vessels, nerves, and organs (4). The transobturator vaginal tape (TOT) approach was developed for female SUI with the aim of avoiding the risk of urethral and bladder injuries with minimal vaginal dissection within a short period of time ${ }^{(5)}$. The procedure is now the most popular technique in many worldwide centers with good results.

\section{PATIENTS AND METHODS}

This study was carried out at the department of Obstetrics and Gynecology, Faculty of Medicine, El-Minya University, from September 2007 to February 2010.

The study included 30 patients diagnosed to have genuine stress urinary incontinence (SUI) demonstrated by history, clinical examination and urodynamic study.

\section{Ethical issue:}

Following ethical guidelines of the research, an approval was taken from the Department Ethical Committee before the start of research. Also written informed consent was taken from each patient.The objectives of the study were explained for each patient, also the details of the used procedure.

\section{Sample size calculation:}

The study consisted of 30 patients, this sample size was calculated by a specific program called EPI-INFO and for calculation of the sample by this method the following data are needed: Prevalence of the female urinary stress incontinence from previous researches. Total number of population under the study. The sample size required can be calculated according to the following formula.

\section{Formula:}

$$
\begin{aligned}
n= & t^{2} \times p(1-p) \\
& m^{2}
\end{aligned}
$$

\section{Description:}

$\mathrm{n}=$ required sample size

$\mathrm{t}=$ confidence level at 95\% (standard value of 1.96)

$\mathrm{p}=$ estimated prevalence of in the project area

$\mathrm{m}=$ margin of error at $5 \%$ (standard value of 0.05 ) 


\section{Patients Eligible Criteria:}

Inclusion Criteria: Genuine stress urinary incontinence by history, examination and urodynamic studies. No contraindications for surgery. Any age was included in the study, post menopausal patients were given HRT to exclude postmemopausal atrophy. HRT was taken in the form of tibolone tablets for 3 months before included in the study.

Exclusion Criteria: Patients with urge or mixed type of incontinence Pregnancy. < 3months post-partum. Systemic disease known to affect bladder function eg spinal cord injuries. Current chemotherapy or radiation therapy. Urethral diverticulum, augmentation cytoplasty, or artificial sphincter. History of recent severe pelvic infections documented by clinical picture and investigations. Known extensive abdominopelvic adhesions. Detrusor instability. Lower urinary tract anomaly. Urogenital prolapse of second degree or more by POP-Q scale. Active malignancy in the pelvis. Anticoagulant therapy and haemorrhagic blood diseasies. Immobile patient. Other gynaecologic pathologies (eg, fibroids, ovarian cysts). Obstructive uropathy.

Diagnosis:

For all patients, physical examination with cough stress test, urine culture and sensitivity and preoperative urodynamics examination were performed. The cough stress test is done with full bladder $(300 \mathrm{ml}$ measured by ultrasound). The patient is asked to cough and bear down; urine is usually lost in small spurts with each cough. Delayed urine loss, particularly large volume loss or complete bladder emptying occurring after coughing, is suggestive of unstable bladder activity. If the stress incontinence is not demonstrated in a standard lithotomy position, the test would be repeated in the standing position with the patient's feet comfortably separated at shoulder width. In cases of associated cystocele and/or rectocele, the test is done before and after insertion of a vaginal pack ${ }^{(6)}$. Cases with a neurogenic bladder or with evident urge incontinence were excluded. If there was a defect in pelvic floor support, it was corrected with an appropriate technique. All subjects received intravenous prophylactic antibiotic therapy at the beginning of surgery.

\section{Urodynamic study:}

All patients underwent urodynamic evaluation preoperatively, The system used in urodynamic evaluation was delphis, KT labories company, Germany. The urodynamic studies were done by Dr / Mohammad Salah El- Badry, Lecture of urology, ElMinya University. The following studies were done: Uroflowmetry. Cystometry. ALPP (abdominal leak point pressure). Pressure-flow study Urodynamic studies were done to confirm genuine stress urinary incontinence and exclude urgency incontinence.

\section{Operative procedure of trans-obturator vaginal tape operation:}

The tape is polypropolene tape called TOT Gyncare, Johnson\& Johnson,USA. The surgical technique was the same as described by de Leval in $2003^{(7)}$. There are ten key procedural steps.

The procedure was performed under spinal anesthesia. The patient was placed in the dorsal lithotomy position. Mark the exit points of the plastic tubes by tracing a horizontal line at the level of the urethral meatus and a second line parallel and $2 \mathrm{~cm}$ above the first line. The exit points are marked on the second line, $2 \mathrm{~cm}$ lateral to the folds of labia majora. Make a 5-mm incision at each exit point. Make a 1$\mathrm{cm}$ midline vaginal incision starting $1 \mathrm{~cm}$ proximal to the urethral meatus. Bluntly dissect to the obturator membrane and perforate it using curved scissors. The pathway of the lateral dissection should be orientated at a $45^{\circ}$ angle from the midline sagittal plane. Insert the winged guide and helical passer. Push the device inward, traversing and slightly passing the obturator membrane. Rotate the helical passer while moving into midline. Facilitate passage of the instrument through skin incision. Grasp the tip of the plastic tube to stabilize then retract helical passer by reverse rotation. Pull plastic tube and tape completely through skin. Repeat the technique on the patient's other side ensuring that the tape lies flat under urethra. Adjust the tape according to your preference, remove plastic sheath, and close incisions.

\section{Post operative evaluation:}

Prophylactic antibiotics is needed for 2 doses only one dose intra-operative and another dose during hospital stay. Collection of data regarding operative time, type of anesthesia, post operative analgesia and duration of hospital stay were done. Intra operative and post operative complications were reported if any. Postoperative complications were recorded and including urinary retention, residual volume, voiding difficulty, de novo urgency, recurrent urinary tract infection and dyspareunia.

\section{Follow up and outcome measures:}

The outcome score of surgical treatment was estimated as follows: the subjective cure $=$ no urine loss during stress, objective cure=no leakage of urine with cough at the bladder capacity of $300 \mathrm{ml}$, and improvement=significantly fewer leakage episodes 
during stress than before surgery. All other patients were classified as failures, even if a clear improvement from the preoperative situation has occurred.

\section{Statistical analysis:}

Comparisons between preoperative and postoperative values were performed with the paired Student's $t$ test Statistical tests $\mathrm{p}<0.05$ was considered statistically significant. Analyses were performed with the Stat View@ statistical software package.

\section{RESULTS}

Thirty patients were enrolled in this study. Follow-up and complete data were available for all these patients. Other patients' characteristics are shown in Table 1. In our study, the mean $( \pm$ SR) age for these patients was $35.4( \pm 7.1)$ years,. In our work, the operative time in these patients ranged from 15 to 22 minutes a from the start of technique. The mean operative time $( \pm \mathrm{SR})$ for these patients was $19.67( \pm 8.06)$ minutes,

In the present study no any case in these patients complicated by intraoperative bleeding either mild or severe bleeding and so no any case required blood transfusion, in these patients, the mean amount of blood loss ( \pm SR) was $80.3 \pm$ (30.52) CC (ranging from 50-110ml)

Table (1): Patients characteristics in the study.

\begin{tabular}{|l|c|}
\hline \multicolumn{1}{|c|}{ Data } & TVT-O (N=30) \\
\hline Age $($ mean \pm SD)(years) & $35.4 \pm 7.1$ \\
\hline $\begin{array}{l}\text { Parity } \\
\text { Mean } \pm \text { SD }\end{array}$ & $6.9 \pm 2.2$ \\
\hline $\begin{array}{l}\text { Body mass index } \\
\text { Mean } \pm \text { SD }\end{array}$ & $27.1 \pm 4.3$ \\
\hline $\begin{array}{l}\text { Morbid obesity (BMI } \geq 35) \\
\text { (number/total number) }\end{array}$ & $1 / 20(5 \%)$ \\
\hline Postmenopausal patients (\%) & $3(15 \%)$ \\
\hline
\end{tabular}

Table (2): Previous gynecological surgery of the patients in the study.

\begin{tabular}{|l|c|}
\hline \multicolumn{1}{|c|}{ Data } & $\begin{array}{c}\text { TVT-O } \\
(\mathbf{N = 3 0 )}\end{array}$ \\
\hline Previous surgery for urinary incontinence & $2(10 \%)$ \\
\hline Previous surgery for prolapse & $3(15 \%)$ \\
\hline
\end{tabular}

Table (3): Intraoperative data of the patients.

\begin{tabular}{|l|c|}
\hline \multicolumn{1}{|c|}{ Data } & $\begin{array}{c}\text { TVT-O } \\
\text { (N=30) }\end{array}$ \\
\hline $\begin{array}{l}\text { Type of anesethia } \\
\text { Regional anesthesia } \\
\text { General anesthesia }\end{array}$ & $\begin{array}{c}20(100 \%) \\
0(0 \%)\end{array}$ \\
\hline $\begin{array}{l}\text { Operative time (min) } \\
\text { Mean } \pm \text { SD }\end{array}$ & $19.67 \pm 8.06$ \\
\hline $\begin{array}{l}\text { Intraoperative blood loss(ml) } \\
\text { mean } \pm \text { SD }\end{array}$ & $80 \pm 30.52$ \\
\hline $\begin{array}{l}\text { Length of hospital stay(days) } \\
\text { Mean } \pm \text { SD }\end{array}$ & $1.46 \pm 0.9$ \\
\hline
\end{tabular}

Regarding intra- operative complications of each technique, no any case in these patients complicated by intraoperative bleeding, bladder injury, urethral injury, vascular injury, intestinal injury and anesthetic complications.

Table (4): Subjective and objective success rates of these patients at 2 years postoperative.

\begin{tabular}{|l|c|}
\hline \multicolumn{1}{|c|}{ Data } & $\begin{array}{c}\text { TVT-O } \\
(\mathbf{N = 3 0 )}\end{array}$ \\
\hline Subjective success rate & $19(95 \%)$ \\
Cured & $0(0 \%)$ \\
Improved & $1(5 \%)$ \\
Failed & $19(95 \%)$ \\
\hline Objective success rate & $0(0 \%)$ \\
Cured & $1(5 \%)$ \\
Improved & \\
Failed & \\
\hline
\end{tabular}

\section{DISCUSSION}

During early cases in this study and because of the previous experience with the fascial slings, it was easy to shift to transobturator sling without considerable difficulty.

Regarding the age, the mean \pm SD of age of these patients $(35.4 \pm 3.1)$. These results were disagree from the results of Taweel and Rabah ${ }^{(8)}$ who reported a mean age of $50 \pm 9$ (range 37-72) years. Also these results were different from the results of de Leval ${ }^{(7)}$ who evaluated the saefty and effectiveness of TVT-O in which the mean age of 107 patients was 62 years (range from 32 years to 82 years, $S D \pm 10.7$ years).

In the present study there was no case in these patients complicated by intraoperative bleeding either mild or severe bleeding and so no case required blood transfusion, these patients, the mean amount of blood loss $( \pm$ SR) was $80.3 \pm$ (30.52) c.c. (ranging from $50-110 \mathrm{ml}$ ) Similarly, Dobson and Co-workers ${ }^{(9)}$ have reported bleeding less than $100 \mathrm{ml}$ in $94 \%$ of their patients using the TVT-O technique. However, Minalgia et al. (10) reported bladder perforation in 3 of 61 patients during TVT-O placement and recommended the routine use of intraoperative cystoscopy in this procedure. However, it should be noted that all three patients with bladder perforation had undergone previous pelvic surgery and that these complications occurred mainly in conjunction with a large C-shaped TVT-O needle.

Regarding intra- operative complications of each technique, no any case in the study complicated by intraoperative bleeding, bladder injury, urethral injury, vascular injury, intestinal injury and anesthetic 
complications in comparison of different techniques of midurethral slings, Silva reported that the shortterm efficacy of TVT-O midurethral slings is comparable with the retropubic slings. In addition, the risk of bladder injury may be the least with inside-out approach. In another study of 390 women who underwent TVT-O (either outside-in or inside-out) for the treatment of SUI, four lower urinary tract injuries $(1 \%)$, two urethral injuries $(0.5 \%)$, and two bladder injuries $(0.5 \%)$ occurred.

In the present study, the subjective and objective cure rate in these patients was $95 \%$

These results were in agreement with the results of Taweel and Rabah ${ }^{(8)}$ who demonstrated a $92 \%$ cure rate after 1 month and $85 \%$ after 2 months in TVT-O group.

These results were in agreement with the results of Waltregny et al. ${ }^{(11)}$ who were found the subjective cure rate was $95 \%(97 / 102)$ at 8 weeks, and subjective cure rates were $94.6 \%$ and $95.4 \%$ at 6 and 12 months, respectively.

Nilsson et al. ${ }^{(12)}$ whose introduced the TVT-O technique in 1996, presented the outcome 11 years after operation: $90 \%$ of the women were still objectively cured at the last follow-up and no late-onset adverse effects of the operation were found. Similar data were reported by Liapis $\boldsymbol{e t}$ al. ${ }^{(13)}$ at 5- and 7-year follow-up.

\section{CONCLUSION}

In this study, transobturator vaginal tape (TOT) is an easy, safe method for the treatment of female SUI The success rate is high with a few complications.

\section{REFERENCES}

1. Milsom I, Ekelund P, Molander U, Arvidsson L, Areskoug B (1993): The influence of age, parity, oral contraception, hysterectomy and menopause on the prevalence of urinary incontinence in women. J Urol., 149:1459-1462.

2. Blaivas JG, Jacobs BZ (1991): Pubovaginal fascial sling for the treatment of complicated stress urinary incontinence. J Urol., 145:1214-1218.

3. Nilsson CG, Kuuva N, Falconer C, Rezapour M, Ulmsten U (2001): Long-term results of the tension-free vaginal tape (TVT) procedure for surgical treatment of female stress urinary incontinence. Int Urogynecol $\mathrm{J}$ Pelvic Floor Dysfunct.,12(2):S5-S8.
4. Boustead GB (2002): The tension-free vaginal tape for treating female stress urinary incontinence. BJU Int., 89:687-693.

5. DeLorme E (2001): Transobturator urethral suspension: mini-invasive procedure in the treatment of stress urinary incontinence in women. Prog Urol., 11:1306-1313.

6. Ghoniem GM, Walters F, Lewis V (1994): The value of the vaginal pack test in largecystoceles. $\mathbf{J}$ Urol., 152:931-934.

7. de Leval J (2003): Novel surgical technique for the treatment of female stress urinary incontinence: transobturator vaginal tape insideout. Eur Urol.,44:724-730.

8. Taweel WA, Rabah DM (2010): Transobturator tape for female stress incontinence: follow-up after 24 months. Can Urol Assoc J., 4(1):33-6.

9. Dobson A, Robert M, Swaby. C, Murphy M, Birch C, Mainprize T (2007): Transobturator surgery for stress urinary incontinence: 1-year follow-up of a cohort of 52 women. Int Urologynecol J Pelvic Floor Dysfunct., 18(1):2732.

10. Minaglia S, Ozel B, Klutke C, Ballard C, Klutke J (2004): Bladder injury during transobturator sling. Urology, 64:376-377.

11. Waltregny D, Bonnet $P$, Reul $O$, de Leval J (2005): Transobturator vaginal tape inside out for the surgical treatment of female stress urinary incontinence: anatomical considerations. J Urol., 173:1223-1228.

12. Nilsson CG, Palva K, Rezapour M et al. (2008): Eleven years prospective follow-up of the tensionfree vaginal tape procedure for treatment of stress urinary incontinence. Int Urogynecol J Pelvic Floor Dysfunct., 19:1043-1047.

13. Liapis A, Bakas P, Creatsas G (2008): Long-term efficacy of tension-free vaginal tape in the management of stress urinary incontinence in women: efficacy at 5-and 7-year follow-up. Int Urogynecol J Pelvic Floor Dysfunct., 19:1509-1512. 